Research Article

\title{
Performance Evaluation of JPCP with Changes of Pavement Mix Design Using Pavement Management Data
}

\author{
Han Jin Oh, ${ }^{1}$ Jun Young Park, ${ }^{1}$ Hyung Bae Kim ${ }^{D},{ }^{1}$ Won Kyong Jung, ${ }^{2}$ and Jung Hun Lee ${ }^{3}$ \\ ${ }^{1}$ Pavement Research Division, Korea Expressway Corporation Research Institute, Hwaseong-si 18489, Republic of Korea \\ ${ }^{2}$ Korea Construction Quality Test Institute, 17555, Republic of Korea \\ ${ }^{3}$ RoadKorea Inc., 18489, Republic of Korea \\ Correspondence should be addressed to Hyung Bae Kim; kimhyun3@ex.co.kr
}

Received 30 January 2019; Accepted 14 May 2019; Published 27 June 2019

Academic Editor: Marco Corradi

Copyright ( $\odot 2019$ Han Jin Oh et al. This is an open access article distributed under the Creative Commons Attribution License, which permits unrestricted use, distribution, and reproduction in any medium, provided the original work is properly cited.

\begin{abstract}
This study aimed to analyze long-term performance of JPCP (jointed plain concrete pavement) according to changes in standard mix design using evaluation of concrete properties based on Korea HPMS (highway pavement management system) and Korea LTPP (long-term pavement performance) data accumulated for over 15 years. The concrete pavements built in the 2010 s by the specification of a durability-based mix design adopted in 2010 were found to have better performance with much fewer surface distresses than the concrete pavements built before 2010 by the specification of a classical strength-based mix design. Also, in order to realize long-life concrete pavement, experimental construction was carried out for high-durability concrete mix design. The performance monitoring data for the construction site implied that the high-durability mix design can make it possible to lead a long-life concrete pavement.
\end{abstract}

\section{Introduction}

Since the first application of concrete pavement to the Namhae Expressway in 1982, concrete pavement has grown rapidly in quantitative terms to account for $65 \%$ $(9,194.6 \mathrm{~km} / \mathrm{lane})$ of Korea Expressway in 2016. In this quantitative growth process, the concrete pavement construction technology has led to the qualitative growth of the concrete mix design technology while experiencing many early-age deteriorations.

This study was conducted to analyze the improvement effects applying advanced technologies in the process of overcoming the early-age deteriorations based on field data, and includes standard mix design criteria for achieving longlife concrete pavement. The field data used in this study were collected from Korea HPMS (highway pavement management system) and Korea LTPP (long-term pavement performance).

The strategies such as pavement design, construction, repair, rehabilitation, maintenance, preservation, and management were determined by using HPMS and LTPP database of analysis of the pavements materials, types, and so on. Wang and Tsai and Ker et al. used LTPP data to develop a reliable faulting prediction model $[1,2]$. Also, Selezneva et al. conducted a study to investigate spatial characteristics of transverse cracking occurring in CRCP and to develop a theoretical model [3]. Zhou et al. [4] and Lu and Denver [5] used LTPP data to improve the IRI model for design of flexible pavement. It is also used for the verification and the comparability analysis of the developed model using LTPP data. Hall et al. used LTPP data for $k$-value verification of concrete pavement [6]. Jamal Khattak and Peddapati analyzed the relationship between the actual performance of the flexible pavements and its relationship with the in situ mechanistic and volumetric properties using LTPP data [7]. Mamlouk and Dosa performed validation of chip seal for preventive maintenance [8]. Hwang and Lee, and Dong and Huang performed the evaluation of effectiveness of each rehabilitation method using LTPP data $[9,10]$. LTPP data were also used to analyze the performance of skid resistance as well as the structural performance of the various pavement types [11, 12]. In other words, the use of LTPP data is 
essential for design and verification to improve pavement performance.

The Korea HPMS was put in place since 2003 to manage pavements at a network level. From 2003, pavement condition surveys were conducted using the automatic pavement condition survey equipment every two to four years depending on traffic volume and years of service. Since 2008, pavement condition surveys have been performed for the entire highway networks every two years, and pavement condition evaluation data from 6 to 7 network level surveys are stored in a database now. Also, in order to analyze pavement performance and effects of construction methods at a project level, Korea LTPP research has continued since 2005, and analyses on pavement performance for a broad range of materials and construction methods are underway.

The performance evaluation of the concrete pavement according to the standard mix design change is performed for the concrete pavement sections constructed in the 2000 s and 2010s at the network level. To this end, for about 10 years, accumulated HPMS database and LTPP research methodology were used.

\section{Mix Design Changes in Concrete Pavement in Korea}

2.1. Early-Age Deteriorations of JPCP in Korea. In the 2000s, concrete pavement faced two big problems as shown in Figure 1: one is cracking by ASR (alkali-silica reaction) and the other is widespread spalling and scaling of joints caused by wet deicing operations in winter in the form of early stage distress. This is considered due to poor concrete durability [13-16]. In 2010, to solve these issues, a new mix design was used, whereby fly ash is added to the binder to prevent ASRcausing distress and durability management indexes are put in place to mitigate distress due to freeze-thaw effects and air void spacing factors are intensively managed [17-20].

\subsection{Changes in Concrete Pavement Mix Design. After massive} research on various performance requirements for concrete pavement, the standard mix design for cement concrete pavement has been modified through six revisions from 1986 to 2010 as listed in Table 1. In Korea, the initial mix design for concrete pavement was established in 1986 for the construction of the Jungbu Expressway with design flexural strength of $4.5 \mathrm{MPa}$ and the first standard concrete pavement mix design was presented in 1996. Afterwards, according to the strength mix design, the standard mix continued to change until the mix design in 2002 in which compared to the initial mix design (cement content: $356-378 \mathrm{~kg} / \mathrm{m}^{3}$ ), the cement content of the mix design in 2002 (cement content: $326 \mathrm{~kg} / \mathrm{m}^{3}$ ) fell around $10-16 \%$. However, major changes in the recent standard mix (2010) for enhanced durability of cement concrete included the introduction of AE (airentrained) and WR (water-reducing) admixtures and replacement of $20 \%$ unit binder with fly ash as an alternative to cement in order to address ASR, spalling, and joint distress due to freeze-thaw effects, which were representative types of distresses of concrete pavement in the 2000s.
2.3. Paradigm Conversion of Concrete Pavement Mix Design. As described above, expressway concrete pavements in Korea were constructed using cement-only binder according to the strength-based mix design standard. In the 2000s, however, prewetted sodium deicers and difficulty in supplying quality aggregates resulted in a sharp increase in ASR distress, spalling at joints, and freeze-thaw distress, raising the need for strategies to solve this. A series of root-cause analyses indicated that durability of concrete mix should be enhanced, and as a result of this, the Comprehensive Plan to Improve Concrete Pavement Quality was established in 2010 as in Table 2. The major improvements under the 2010 plan included the introduction of AE and WR admixtures, reduction of unit cement content, and application of fly ash as a replacement of cement, which aimed at enhanced cement concrete constructability and durability indexes. At the core of the comprehensive plan were the adoption of air void spacing factor and change of mix design. More specifically, air void spacing factor standard $(0.2 \mathrm{~mm}$ or less) was added to air voids among the durability. And, in the case of mixing, the unit binder weight was increased $\left(326 \longrightarrow 350 \mathrm{~kg} / \mathrm{m}^{3}\right)$ with 20-percent fly ash. On top of this, the standard for entrained air voids was increased $(4-6 \% \longrightarrow 5-7 \%)$, and management of $\mathrm{AE}$ and $\mathrm{WR}$ admixtures was strengthened. This represents a paradigm shift from the existing strengthbased mix design to a mix design focusing on concrete durability in Korea [21-25].

Despite major concrete pavement mix design improvements such as the introduction of AE admixture and water-reducing admixtures and the application of cement containing fly ash admixtures, further quantitative studies are still in need for the analysis of strength, durability, and performance according to changes in concrete pavement mix design.

Consequently, this study performed a performance evaluation according to major changes in the standard mix design of concrete pavement and examined how the mix design characteristics for concrete pavement affect its performance. In particular, beyond the existing strength-based mix design, a durability-based mix design was used to conduct a pavement condition survey and evaluation of properties of concrete pavement materials for comparison.

\section{Pavement Performance Evaluation and Survey Sections}

3.1. Pavement Performance Evaluation. The performance evaluation for concrete pavement depending on changes in the standard mix design was based on the HPMS data at a network level and data on properties from in situ core specimens.

HPMS is expressed as HPCI (highway pavement condition index) and calculated for concrete pavement using IRI (International Roughness Index) and SD (surface distress area) as in equation (1). Pavement condition surveys were conducted using an automatic pavement condition survey vehicle that can travel up to $80 \mathrm{~km} / \mathrm{h}$ and collect data such as road profiles and pavement surface photo for SD analysis every $10 \mathrm{~m}$ distance and generated HPCI: 


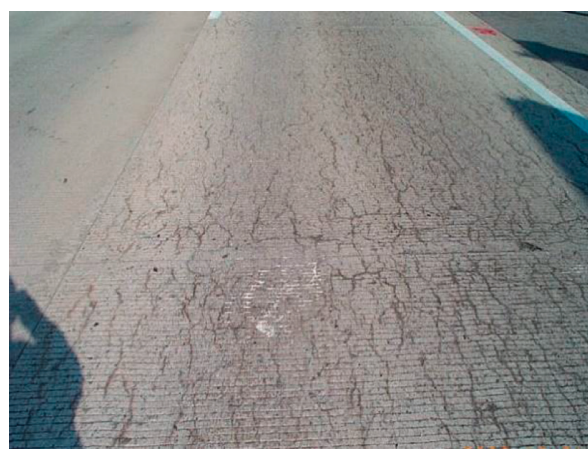

(a)

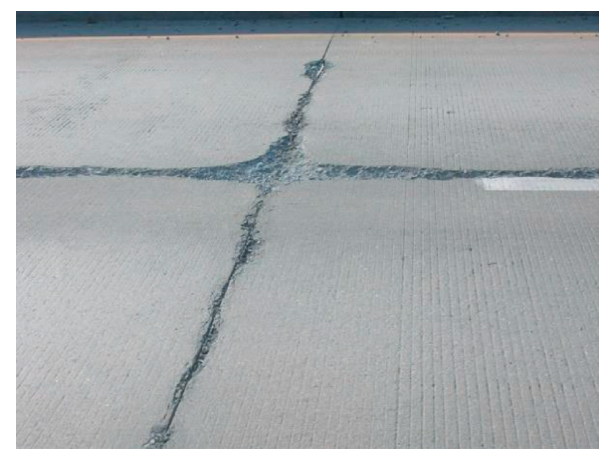

(b)

FIgURe 1: Typical distresses of JPCP in Korea. (a) ASR distresses. (b) Joint freeze-thawing distress.

TABLE 1: Mix design changes of expressway concrete pavement in Korea.

\begin{tabular}{|c|c|c|c|c|c|c|c|c|c|c|}
\hline \multirow{3}{*}{ Year } & \multirow{3}{*}{ Slump (mm) } & \multirow{3}{*}{ Air (\%) } & \multirow{3}{*}{ Water/binder ratio } & \multicolumn{5}{|c|}{ Unit weight $\left(\mathrm{kg} / \mathrm{m}^{3}\right)$} & \multicolumn{2}{|c|}{ Admixtures } \\
\hline & & & & \multirow{2}{*}{ Water } & \multicolumn{2}{|c|}{ Binder } & \multirow{2}{*}{ Sand } & \multirow{2}{*}{ Gravel } & \multirow{2}{*}{$\mathrm{AE}(\%)$} & \multirow{2}{*}{ WR (\%) } \\
\hline & & & & & Cement & Fly ash & & & & \\
\hline 1986 & $30-50$ & $3-6$ & & $153-170$ & $356-378$ & - & $595-694$ & $1135-1272$ & 0.03 & - \\
\hline 1996 & $40-60$ & $4-6$ & 0.45 & 151 & 336 & - & 678 & 1162 & 0.15 & - \\
\hline 2002 & $40-60$ & $4-6$ & & 147 & 326 & - & 692 & 1122 & 0.3 & - \\
\hline 2010 & $40-60$ & $5-7$ & 0.43 & 150 & 280 & 70 & 630 & 1150 & 0.02 & 0.3 \\
\hline
\end{tabular}

Table 2: Summary of Comprehensive Plan to Improve Concrete Pavement Quality (2010).

\begin{tabular}{|c|c|}
\hline Item & Detail \\
\hline Introduction of spacing factor & $\begin{array}{c}\text { (i) Add standard air void spacing factor to durability } \\
\text { indexes }(0.2 \mathrm{~mm} \text { or less })\end{array}$ \\
\hline Change of concrete pavement mix design standard & $\begin{array}{l}\text { (ii) Increase unit binder weight }\left(326 \longrightarrow 350 \mathrm{~kg} / \mathrm{m}^{3} \text {, }\right. \\
\text { fly ash } 20 \%) \\
\text { (iii) Adjust air voids content }(4-6 \% \longrightarrow 5-7 \%) \\
\text { (iv) Strictly manage admixtures (air-entrained, water- } \\
\text { reducing, etc.) }\end{array}$ \\
\hline
\end{tabular}

$$
\text { for } \begin{aligned}
\mathrm{HPMS}: \mathrm{HPCI}= & 5-0.8 \times \mathrm{IRI}^{0.7}-0.85 \\
& \times \log (1+2.5 \times \mathrm{SD}),
\end{aligned}
$$

where $\mathrm{HPCI}=$ calculated with $\mathrm{SD}_{0}, \quad \mathrm{IRI}=$ International Roughness Index $(\mathrm{m} / \mathrm{km})$, and SD = unified surface distress area excluding patched section $\left(\mathrm{m}^{2}\right)$.

The SD means an unified surface distress which can be obtained by the summation of the deteriorated areas with line cracks (crack length $(\mathrm{m}) \times 0.3 \mathrm{~m})$, spalls, surface deteriorations, and exclusion of patched areas with partial or full depth repair. The reason for excluding the repair section from the SD calculation is that the pavement condition is considered to be improved through the maintenance budget input when the maintenance method is applied.

For HPMS, HPCI of 5.0 represents the best pavement performance, and depending on $\mathrm{HPCI}_{0}$, IRI, and $\mathrm{SD}$ values, seven classifications for management are established as in Table 3 .

However, in case of LTPP, because it is the purpose of analysis of performance life cycle of the pavement, it is desirable to regard the repair section as a damaged area. The patched area is included in the SD calculation, and HPCI is calculated as shown in equation (2) [26]. Therefore, in this study, $\mathrm{HPCI}_{1}$ and $\mathrm{SD}_{1}$ were used to analyze the performance of JPCP depending on concrete mix design change:

$$
\text { for LTPP : } \begin{aligned}
\mathrm{HPCI}_{1}= & 5-0.8 \times \mathrm{IRI}^{0.7}-0.85 \\
& \times \log \left(1+2.5 \times \mathrm{SD}_{1}\right)
\end{aligned}
$$

where $\mathrm{HPCI}_{1}=$ calculated with $\mathrm{SD}_{1}$, IRI = International Roughness Index $(\mathrm{m} / \mathrm{km})$, and $\mathrm{SD}_{1}=$ unified surface distress area including patched section $\left(\mathrm{m}^{2}\right)$.

Also, the analysis of concrete properties using in situ core specimens resulted in the measurement of converted flexural strength using compressive strength and split tensile strength as concrete strength management factors and that of air void spacing factor as a factor of durability management. As the Korean highway bridge design codes (limit state design) require that the converted flexural strength via split tensile strength be determined approximately [27], this study measured the split tensile strength using in situ core specimens and then calculated the flexural strength. 
TABLE 3: Grade of pavement performance index of HPCI component for HPMS.

\begin{tabular}{lccccc}
\hline Grade & HPCI & IRI & SD $\left(\mathrm{m}^{2}\right)$ & SD $(\%)^{*}$ & Action \\
\hline 1 & 4.0 or more & Below 1.5 & 0 & 0 & Do nothing \\
2 & $4.0-3.5$ & $1.5-2.0$ & Less 1.0 & 0.3 & Preventive maintenance \\
3 & $3.5-3.25$ & $2.0-2.5$ & $1.0-18$ & $0.3-5$ & Maintenance and repair if necessary \\
4 & $3.25-3.0$ & $2.5-3.0$ & $18-36$ & $5-10$ & Maintenance and repair \\
5 & $3.0-2.5$ & $3.0-3.5$ & $36-52$ & $10-15$ & Rehabilitation, if necessary \\
6 & $2.5-2.0$ & $3.5-4.0$ & $52-72$ & $15-20$ & Rehabilitation \\
7 & Below 2.0 & 4.0 or more & 72 or more & 20 or more & Preferred rehabilitation \\
\hline
\end{tabular}

${ }^{*}$ SD (\%): unified surface distress per unit area of pavement surface.

3.2. Survey Sections. If the paradigm conversion of mix design makes an effect on the quality improvement on concrete pavement of performance, a meaningful difference of the concrete pavement should be made between the concrete pavement sections built in 2000s and 2010s. In order to identify the difference, the data analysis for the comparison of the pavement performance was conducted using HPMS data. Two data groups from the concrete pavement sections built in 2000s and 2010s, respectively, were divided and separately analyzed. Then, the concrete pavement performance data of these groups were compared.

Three sections among concrete pavements built in $2010 \mathrm{~s}$ (durability-based mix) were selected as shown in Table 4, and five sections among concrete pavements built in 2000s (strength-based mix) were selected as shown in Table 5. For all lanes of these selected sections, the pavement performance data stored in HPMS database were extracted and analyzed [28-41]. Two- or three-cored specimens were obtained for each section. Properties of cored specimens from the selected sections were evaluated.

\section{Performance Evaluation of JPCP}

4.1. HPMS Data: $H P C I_{1}, I R I$, and $S D_{1}$. Figure 2 illustrates results from pavement condition surveys according to changes in the standard mix design for concrete pavement. The routes constructed in the 2010s are represented by a solid line and those built in the 2000s in dotted line, with indications of both-direction averages for the outermost lanes (design lane) of each route. Since changes in pavement performance are more apparent in the inside lane (2nd lane) than in the passing lane (1st lane) for reasons such as heavy traffic, the data of inside lane were used for analysis.

Figure 2(a) shows $\mathrm{HPCI}_{1}$ changes over service life. Although initial measurements of each have slight differences, all routes were found to exhibit good condition of 3.5 or over at $\mathrm{HPCI}_{1}$ for a service life of 10 years or so without a noticeable change and the routes built in the 2000s were a bit higher in their $\mathrm{HPCI}_{1}$ than those built in the 2010s. There are no data available for 10 years later for the routes constructed in the 2010s as they have been in service for seven to eight years, but $\mathrm{HPCI}_{1}$ values for those constructed in the 2000 s sharply fall from around 12 years of service. In addition, $\mathrm{HPCI}_{1}$ levels of some of the routes constructed in the $2000 \mathrm{~s}$ appear to fall and then rise again. The increase of $\mathrm{HPCI}_{1}$ can be explained by the fact that sections with low $\mathrm{HPCI}_{1}$ were excluded from the analysis by applying asphalt overlays on the sections suffering from severe pavement distress as a concrete pavement maintenance solution, and the survey was conducted only on the concrete pavements showing relatively better performance.

Figure 2(b) describes IRI changes depending on years of service. All routes repeat increase and decrease in IRI and eventually increase to some degree over the service period, but they still remain in good condition without clear change. It is considered that IRI decreased because diamond grinding was widely used across the concrete pavement to enhance the ride quality along the expressways and to manage pavement condition. In addition, the routes constructed in the 2000s with a service life of 10 years or less were found to have lower IRI and exhibit better roughness, compared to those built in the 2010s.

Figure 2(c) shows $\mathrm{SD}_{1}(\%)$ changes by service life. Recent surveys revealed that there is no apparent increase in surface distress of the routes constructed in the 2010s. In contrast, those built in the 2000 displayed widespread surface distress from the service lives of 6 to 8 years. Like IRI, increase and decrease in $\mathrm{SD}_{1}$ occurred in the routes built in the 2000s. If $\mathrm{SD}_{1}$ increased, ASR, joint spalling, and freeze-thaw distress happened as major damages of JPCPs laid in the 2000s as described earlier. The decrease in $\mathrm{SD}_{1}$ was thought to be due to the fact that surface distress was removed with diamond grinding to raise IRI or AP overlays were applied to severely damaged sections, which were then excluded from the analysis.

Two major factors affecting $\mathrm{HPCI}_{1}$ of concrete pavement, IRI and $\mathrm{SD}_{1}$, were found to be directly influenced by maintenance activities like diamond grinding and AP overlay intended to maintain serviceability grades for expressways. $\mathrm{HPCI}_{1}$ for the routes built in the 2000s apparently decreased in ten years of service, but IRI showed no apparent change over the service life by applying roughness improvement strategies such as diamond grinding. This indicates that it would be appropriate to analyze changes in $\mathrm{SD}_{1}$ for performance evaluation according to changes in the standard mix design for concrete pavement.

The $\mathrm{HPCI}_{1}$, IRI, and $\mathrm{SD}_{1}$ results in the maximum distress occurrence year by route are presented in Table 6 and Figure 3. For the routes built in the 2010s (\#65, \#27, \#45-1), the last survey results refer to the maximum distress occurrence year and the routes built in the 2000s (\#45-2, \#45-3, $\# 15$, \#35, \#55) represent sections having the highest $\mathrm{SD}_{1}$ during the survey.

The average $\mathrm{HPCI}_{1}$ of the sections built in the 2010s was 3.88, representing better performance, compared to the 
TABLE 4: Summary of concrete pavement sections built in 2010s for performance data analysis.

\begin{tabular}{lcccc}
\hline Route name (\#no.) & $\begin{array}{c}\text { IC./Jct. to IC./Jct. } \\
\text { length (km) }\end{array}$ & $\begin{array}{c}\text { Construction } \\
\text { year }\end{array}$ & $\begin{array}{c}\text { Length of concrete pavement } \\
\text { section (km/line) }\end{array}$ & Data survey year \\
\hline Donghae (\#65) & Hajodae-Yangyang (9.7) & 2013 & 31.7 & $2014,2015^{*}, 2017$ \\
Suncheon Wanju (\#27) & Namwon-Wanju (59.5) & 2010 & 204.0 & $2012,2014,2016^{*}$ \\
Jungbu Naeryuk (\#45-1) & Namyeoju-Yangpyeong (34.5) & 2010 & 117.8 & $2012,2014,2015^{*}, 2017$ \\
\hline
\end{tabular}

*Evaluation of concrete properties using in situ core specimens.

TABLE 5: Summary of concrete pavement sections built in 2000s for performance data analysis.

\begin{tabular}{|c|c|c|c|c|}
\hline Route name (\#no.) & $\begin{array}{l}\text { IC/JC to IC/JC } \\
\text { length }(\mathrm{km})\end{array}$ & $\begin{array}{c}\text { Construction } \\
\text { year }\end{array}$ & $\begin{array}{l}\text { Length of concrete } \\
\text { pavement } \\
\text { section }(\mathrm{km} / \text { line })\end{array}$ & Data survey year \\
\hline $\begin{array}{l}\text { Jungbu Naeryuk } \\
(\# 45-2)\end{array}$ & Gimcheon-Nakdong (24.8) & 2001 & 84.64 & 2005, 2009, 2011, 2013, 2015*, 2017 \\
\hline $\begin{array}{l}\text { Jungbu Naeryuk } \\
(\# 45-3)\end{array}$ & Goisan-Yeoju (55.9) & 2002 & 174.4 & $2005,2006,2009,2011,2013,2014,2015^{*}$ \\
\hline Seohaean (\#15) & $\begin{array}{c}\text { Dongseocheon-Dangjin } \\
(103.1)\end{array}$ & 2001 & 334.9 & 2004, 2007, 2009, 2011, 2013, 2015, 2017 \\
\hline $\begin{array}{l}\text { Daejeon Tongyoung } \\
(\# 35)\end{array}$ & Jangsu-Sanae (72.3) & 2001 & 218.0 & $2006,2008,2010,2012,2014,2016^{*}$ \\
\hline Jungang (\#55) & Danyang-Chuncheon (139.1) & 2000 & 432.7 & $2005,2007,2009,2011,2013,2015^{*}, 2016$ \\
\hline
\end{tabular}

*Evaluation of concrete properties using in situ core specimens.

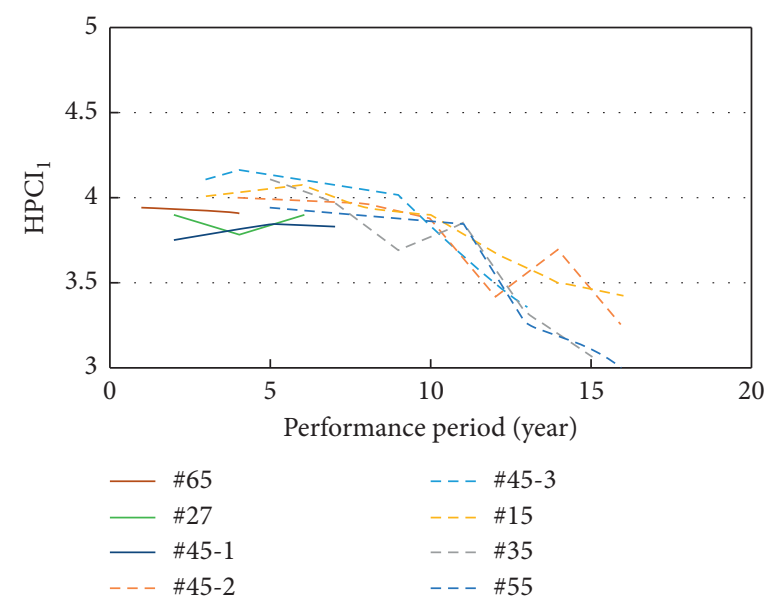

(a)
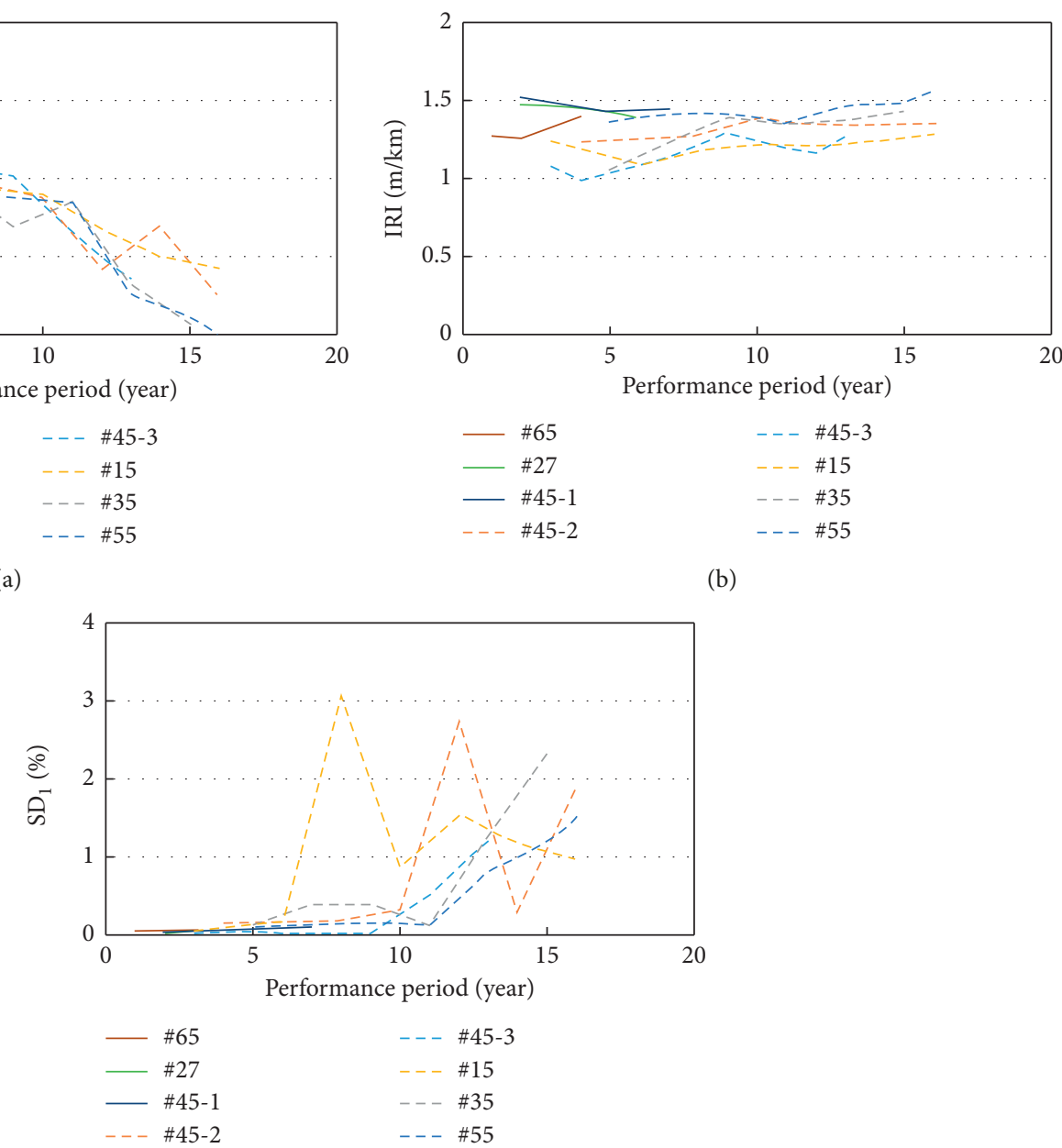

$---\# 45-3$
$---\# 15$
$---\# 35$
$---\# 55$

(b)

(c)

FIGURE 2: Pavement condition change according to the whole performance period. (a) $\mathrm{HPCI}_{1}$. (b) IRI (m/km). (c) $\mathrm{SD}_{1}(\%)$. 
average of those built in the 2000s at 3.30. The standard deviation of the sections built in the 2010s was 0.42 , lower than 0.76 of those built in the 2000s $(p=0.001)$. IRI values showed that all sections were in good condition for service, which suggests that resurfacing applications like diamond grinding enhanced IRI across the expressways nationwide. As far as $\mathrm{SD}_{1}$ was concerned, the average cracking ratio of the sections constructed in the 2010 s hit $0.09 \%$, remarkably lower than $1.87 \%$ of those constructed in the 2000 s, and the standard deviation of 0.63 for the sections built in the 2010 s was profoundly lower than 3.73 of those built in the 2000s $(p=0.012)$. Statistical comparisons between 2010s and 2000s were made using Student's $t$-test; $p<0.05$ was used to establish statistical significance.

4.2. Properties of Concrete: Strengths and Spacing Factor. In situ core specimens were collected from every route in order to assess surface distress using pavement condition survey data and to carry out property evaluation of concrete pavement according to changes in the standard mix. The compressive strength and split tensile strength of concrete pavement were measured, and flexural tensile strength was estimated from the split tensile strength. Moreover, spacing factor as one of the key changes in the 2010 mix in terms of durability was measured by ASTM C457 [42], and the evaluation results are shown in Table 7.

The compressive strength evaluation showed that all the sections displayed a compressive strength of $30 \mathrm{MPa}$ or over and compressive strengths of the routes built in the 2000s were higher than those built in the 2010s. In addition, the evaluation of converted flexural tensile strength found that the results were similar in magnitude between the routes built in the 2010s and 2000s but failed to meet the design flexural strength of $4.5 \mathrm{MPa}$ to some degree. In concrete strength, the sections built in the 2000s were found to have higher compressive strengths than those built in the 2010s and similar flexural tensile strengths, which is, however, considered inappropriate to be accepted as the differences according to changes of concrete mix design because these results came from the difference in years of service.

The air void spacing factor as a durability management item for concrete pavement was significantly higher in the sections constructed in the $2000 \mathrm{~s}$ at $343 \mu \mathrm{m}$, while that of the routes built in the $2010 \mathrm{~s}$ appeared to be fair at $206 \mu \mathrm{m}$. The concrete pavements placed before the Comprehensive Plan to Improve Concrete Pavement Quality in 2010 adhered to the strength-based mix design and appeared to exhibit somewhat disadvantageous levels of spacing factor that affects concrete durability, despite high concrete strengths.

In contrast, the sections built in the 2010s followed the durability-based mix design, not the existing strength-based design concept, which resulted in concrete strengths such as compressive strength and split tensile strength that were good enough even though lower than the sections built in the 2000s, and the air void spacing factor affecting concrete durability was considerably enhanced.

The findings from the pavement condition surveys and evaluation of properties using in situ core specimens showed that the concrete pavement sections built in the 2010s after the standard mix improvement had strikingly less surface distress as a major type of damage of the concrete pavements laid in the 2000s and enhanced durability. As a result, concrete pavements placed in the 2010 s are expected to show better performance than those in the 2000s.

\section{Experimental Construction to Improve Standard Mix Design for Long-Life Concrete Pavement}

5.1. Experimental Construction for Long-Life and High-Durability Concrete Mix Design. The changes in the durabilitybased concrete pavement standard mix in 2010 have led to preventing major types of distress of the existing concrete pavement and ensuring excellent pavement performance. Another improvement of the standard mix including increase of unit binder weight and enhanced design flexural strength was made for long-life concrete pavement [43-48]. For this purpose, experimental constructions by mix design were put in place by enhancing the design flexural strength from $4.5 \mathrm{MPa}$ to $5.0 \mathrm{MPa}$.

A high-durability concrete mix design for long-life concrete pavement was established by increasing unit binder weight as shown in Table 8 on the basis of the current standard mix with a design flexural strength of $4.5 \mathrm{MPa}$ (2010 mix design). The applied concrete mix design had three variables in total: two types of mix that increased unit binder weight from the existing $20 \%$ fly ash content and one OPC (ordinary Portland cement) mix that increased unit cement content only. The experimental constructions were located on a new construction expressway in June 2016. In order to investigate the effect of such increased design flexural strength on concrete pavement performance, concrete durability was evaluated for around one year of construction, using in situ core specimens by concrete pavement age.

5.2. Properties of Concrete. In order to evaluate concrete durability of the experimental constructions using highstrength concrete pavement, flexural strength, scaling resistance, freeze-thaw resistance, and RCPT (resistance concrete penetration test) were conducted on in situ core specimens by the age of concrete pavement. Results of such durability evaluation by concrete age are shown in Table 9.

Compared to the existing standard mix (FAC 350) for concrete pavement, the high-strength concrete pavement (FAC 408, FAC 390) mix showed enhanced durability properties such as freeze-thaw resistance and chlorine ion penetration resistance by $40-60 \%$ or over. When compared to the existing mix (FAC 350), the OPC 388 mix that increased unit cement content only showed a bit lower chlorine ion penetration resistance. Considering the road management practices in Korea where deicers are widely used in winter, the OPC mix seems inappropriate as its RCPT is still disadvantageous even after around one year of construction although it provides extremely high flexural strength. On top of that, from the fact that the primary 
TABLE 6: HPMS data at the time of maximum distresses occurrence.

\begin{tabular}{|c|c|c|c|c|c|c|c|c|}
\hline \multirow{2}{*}{ Route (\#) } & \multirow{2}{*}{ Construction year } & \multirow{2}{*}{ Age of maximum distresses occurrence (year) } & \multicolumn{2}{|c|}{$\mathrm{SD}_{1}$} & \multicolumn{2}{|c|}{ IRI } & \multicolumn{2}{|c|}{$\mathrm{HPCI}_{1}$} \\
\hline & & & Mean & Stdev & Mean & Stdev & Mean & Stdev \\
\hline$\# 65$ & 2013 & $5(2017)$ & 0.08 & 0.62 & 1.39 & 0.58 & 3.91 & 0.39 \\
\hline$\# 27$ & 2010 & $7(2016)$ & 0.08 & 0.56 & 1.39 & 0.58 & 3.90 & 0.43 \\
\hline \multirow[t]{2}{*}{ \#45-1 } & 2010 & $8(2017)$ & 0.11 & 0.63 & 1.44 & 0.54 & 3.83 & 0.44 \\
\hline & & 2010s average & 0.09 & 0.60 & 1.41 & 0.57 & 3.88 & 0.42 \\
\hline$\# 45-2$ & 2001 & $12(2013)$ & 2.77 & 5.57 & 1.34 & 0.54 & 3.42 & 0.68 \\
\hline$\# 45-3$ & 2002 & $13(2015)$ & 1.21 & 1.98 & 1.27 & 0.54 & 3.36 & 0.82 \\
\hline$\# 15$ & 2001 & $12(2013)$ & 1.55 & 4.93 & 1.21 & 0.54 & 3.67 & 0.73 \\
\hline \#35 & 2001 & $15(2016)$ & 2.33 & 4.13 & 1.43 & 0.58 & 3.07 & 0.83 \\
\hline \multirow[t]{2}{*}{ \#55 } & 2000 & $16(2016)$ & 1.50 & 2.06 & 1.56 & 0.63 & 3.00 & 0.75 \\
\hline & & 2000s average & 1.87 & 3.73 & 1.36 & 0.57 & 3.30 & 0.76 \\
\hline
\end{tabular}

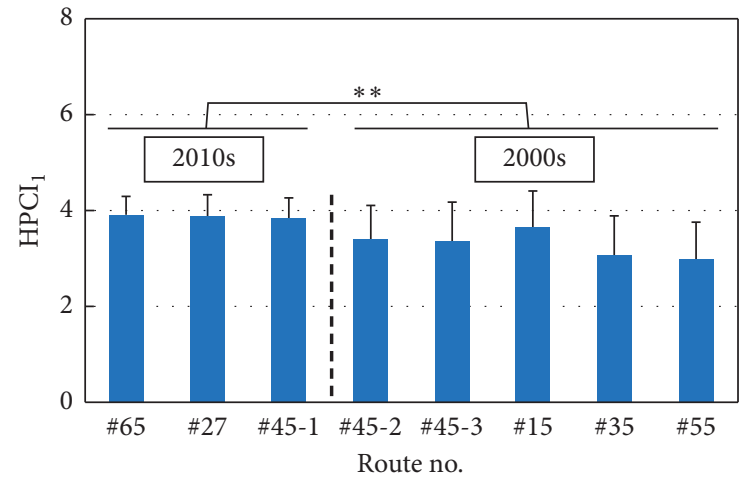

(a)

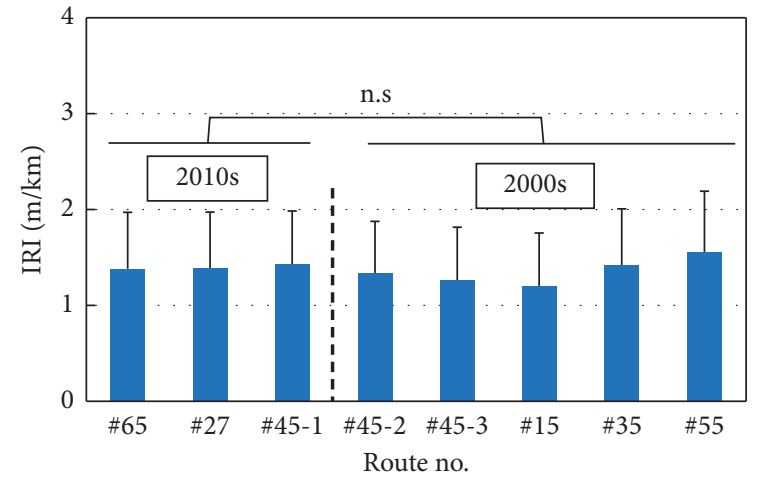

(b)

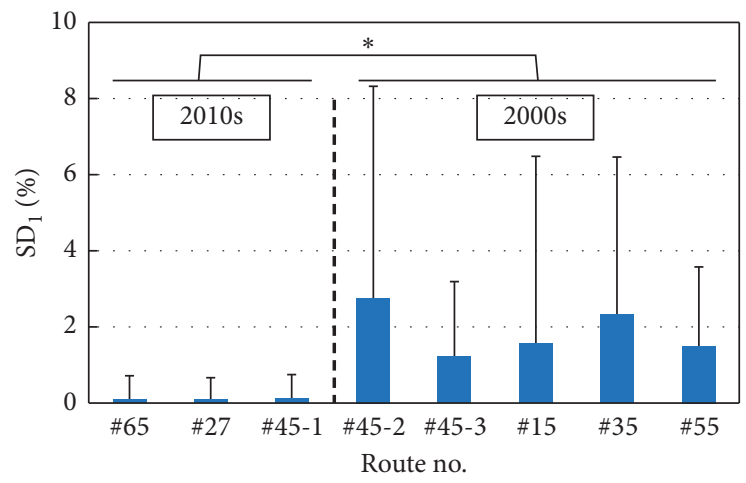

(c)

FIGURE 3: Pavement condition according to maximum distresses occurrence year. (a) $\mathrm{HPCI}_{1}$. (b) IRI (m/km). (c) SD $(\%)$.

TABLE 7: Test result of concrete properties using in situ core specimens.

\begin{tabular}{ccccc}
\hline & & Compressive strength $(\mathrm{MPa})$ & Calibrated flexural strength $(\mathrm{MPa})$ & Spacing factor $(\mu \mathrm{m})$ \\
\hline \multirow{2}{*}{$2010 \mathrm{~s}$} & Average & 40.73 & 4.39 & 205.9 \\
& Stdev & 6.53 & 0.66 & 24.0 \\
\hline \multirow{2}{*}{$2000 \mathrm{~s}$} & Average & 47.36 & 4.34 & 343.0 \\
& Stdev & 4.31 & 0.36 & 31.6 \\
\hline
\end{tabular}

pavement damage is freeze-thaw distress at joint in Korea, the FAC 390 and FAC 408 mixes offering excellent freezethaw resistance are considered more adequate for long-life concrete pavement rather than the existing FAC 350 mixture.
Therefore, in this study performed experimental constructions for high-strength concrete mix that meets design high-durability mix design for long-life concrete pavement and assessed concrete durability. As a result, the concrete pavement mix containing a $20 \%$ fly ash and increased unit 
TABLE 8: Experimental constructions to improve standard mix design of concrete pavement.

\begin{tabular}{lcccc}
\hline \multirow{2}{*}{ Classification } & \multicolumn{2}{c}{ Fly ash 20\% blended cement (FAC) } & \multicolumn{2}{c}{ Ordinary Portland cement (OPC) } \\
& FAC $350^{*}$ & FAC 408 & FAC 390 & OPC 388 \\
\hline Unit binder content $\left(\mathrm{kg} / \mathrm{m}^{3}\right)$ & 350 & 408 & 390 & 388 \\
Unit water content $\left(\mathrm{kg} / \mathrm{m}^{3}\right)$ & 150 & 155 & 148 & 152 \\
Water/Binder ratio & 0.43 & 0.38 & 0.38 & 0.40 \\
Design flexural strength $(\mathrm{MPa})$ & 4.5 & 5.0 & 5.0 & 5.0 \\
\hline
\end{tabular}

${ }^{*}$ The 2010 concrete pavement standard mix design as in Table 2.

TABLE 9: Results of durability evaluation to improve standard mix design of concrete pavement.

\begin{tabular}{lcccc}
\hline Type & Flexural strength $(\mathrm{MPa})$ & Scaling $\left(\mathrm{kg} / \mathrm{m}^{3}\right)$ & Freezing-thawing $(\%)$ & RCPT $(\mathrm{C})$ \\
\hline Test method & ASTM C78 [49] & ASTM C672 [50] & ASTM C666 [51] & ASTM C1202 [52] \\
Core specimen collection (days) & 28 & 190 & 330 & 28 \\
FAC 350 & 4.70 & 0.223 & 83.2 & 190 \\
FAC 408 & 5.12 & 0.130 & 97.9 & 4,719 \\
FAC 390 & 5.83 & 0.067 & 5,146 & 902 \\
OPC 388 & 6.10 & 0.425 & 97.8 & 1,398 \\
\hline
\end{tabular}

binder weight with the enhanced design flexural strength can provide higher durability and realize long-life concrete pavement.

\section{Conclusions}

This study investigated the applicability of the durabilitybased standard mix design in order to mitigate distresses caused by surface cracking by ASR, joint spalling, and freezethaw effects, which were major types of damages occurred in the 2000s along the concrete pavement network across Korea. To this end, performance changes in concrete pavement were analyzed by carrying out evaluations of properties using in situ core specimens and HPMS data accumulated for more than 15 years for five sections built in the 2000s and three sections built in the 2010s since the improvements in the standard mix design in 2010 that worked towards the durability-based mix from the strengthbased mix. The findings from the analysis confirmed the appropriateness of the durability-based standard mix improvements, on the basis of which experimental constructions for long-life concrete pavement were conducted, producing an improved standard mix. The following conclusions were drawn from this study.

It was found that an analysis of changes in $\mathrm{SD}_{1}$ is more appropriate than $\mathrm{HPCI}_{1}$ and IRI for performance evaluation according to changes in standard mix design of concrete pavement with statistical significance. In the routes constructed under the durability-based standard mix design in the 2010s, occurrence and increase of $\mathrm{SD}_{1}$ was significantly slow until seven years of service, but $\mathrm{SD}_{1}$ increased rapidly in the routes built in the 2000s from six years of service.

By applying the durability-based mix design, instead of the existing strength-based design concept, the sections constructed in the 2010s appeared to display highly enhanced air spacing factor that affects concrete durability even though concrete strengths such as compressive strength and flexural strength were a bit lower than the pavements laid in the 2000s. As a consequence, the concrete pavement sections incorporating improvements in the durabilitybased standard mix design was found to achieve enhanced durability, which is expected to help ensure long-term performance of concrete pavement.

This study conducted the experimental construction and concrete durability evaluation for high-strength concrete mix design that meets design flexural strength of 5.0 MPa for long-life concrete pavement. The findings from this study revealed that the concrete pavement mix containing $20 \%$ fly ash and increased unit binder weight with the enhanced design flexural strength will be able to provide better durability and realize long-life concrete pavement, resulting in the proposal of an improved standard mix design for better concrete pavement quality and performance.

\section{Data Availability}

The HPMS and concrete properties data used to support the findings of this study have not been made available because the data were supplied by Korea Expressway Corporation under license.

\section{Conflicts of Interest}

The authors declare that they have no conflicts of interest.

\section{Acknowledgments}

This study was conducted under research project (Development of High-Performance Concrete Pavement Maintenance Technology to Extend Roadway Life) (Project No: 18TLRP-B146707-01) funded by the Ministry of Land, Infrastructure and Transport (MOLIT) and the Korea Agency for Infrastructure Technology Advancement (KAIA). The authors would like to thank the members of research team, MOLIT and KAIA, for their guidance and support throughout the project. 


\section{References}

[1] W.-N. Wang and J. Y. Tsai, "Back-propagation network modeling for concrete pavement faulting using LTPP data," International Journal of Pavement Research and Technology, vol. 6, no. 5, pp. 651-657, 2013.

[2] H. W. Ker, Y. H. Lee, and C. H. Lin, "Development of faulting prediction models for rigid pavements using LTPP database," International Journal of Pavement Research and Technology, vol. 5, pp. 658-666, 2013.

[3] O. Selezneva, M. Darter, D. Zollinger, and S. Shoukry, "Characterization of transverse cracking spatial variability: use of long-term pavement performance data for continuously reinforced concrete pavement design," Transportation Research Record: Journal of the Transportation Research Board, vol. 1849, no. 1, pp. 147-155, 2003.

[4] G. Zhou, W. Linbing, and L. Yang, IRI Model Enhancement for Flexible Pavement Design Using LTPP Data, Transportation Research Board, Washington, DC, USA, 2008.

[5] P. Lu and T. Denver, "Pavement pre-and post-treatment performance models using LTPP data," Journal of the Transportation Research Forum, vol. 51, no. 3, pp. 67-888, 81.

[6] K. T. Hall, M. I. Darter, T. E. Hoerner, and L. Khazanovich, "LTPP data analysis. Phase I: validation of guidelines for $\mathrm{K}$-value selection and concrete pavement performance prediction," Technical Report FHWA-RD-96-198, Federal Highway Administration (FHWA), Washington, D.C., USA, 1997.

[7] M. Jamal Khattak and N. Peddapati, "Flexible pavement performance in relation to in situ mechanistic and volumetric properties using LTPP data," ISRN Civil Engineering, vol. 2013, Article ID 972020, 7 pages, 2013.

[8] M. S. Mamlouk and M. Dosa, "Verification of effectiveness of chip seal as a pavement preventive maintenance treatment using LTPP data," International Journal of Pavement Engineering, vol. 15, no. 10, pp. 879-888, 2014.

[9] E. S. Hwang and S. W. Lee, "A study on the effect of rehabilitation methods in aged concrete pavement using the LTPP data," Journal of the Korean Society of Civil Engineers, vol. 27, no. 3, pp. 325-332, 2007.

[10] Q. Dong and B. Huang, "Evaluation of effectiveness and costeffectiveness of asphalt pavement rehabilitations utilizing LTPP data," Journal of Transportation Engineering, vol. 138, no. 6, pp. 681-689, 2011.

[11] S. W. Lee, S. K. Rhee, and S. J. Chon, "A study for decreasing rate of skid resistance of tinned concrete pavement based on the LTPP data," Journal of the Korean Society of Civil Engineers, vol. 25, no. 1D, p. 85, 2005.

[12] A. M. Ahammed and S. L. Tighe, "Evaluation of concrete pavements surface friction using LTPP data: preliminary analysis and texture performance models," in Proceedings of the 86th Transportation Research Board Annual Meeting, Washington, D.C., USA, January 2007.

[13] M. Pigeon and R. Pleau, Durability of Concrete in Old Climates, E \& FN Spon, London, UK, 1995.

[14] D. D. Magura, “Air-void analyzer evaluation," Report No. FHWA-SA-96-062, Federal Highway Administration (FHWA), Washington, D.C., USA, 1996.

[15] M. Radlinski, J. Olek, M. Del Mar Arribas et al., "Influence of air-void system parameters on freeze-thaw resistance of pavement concrete-lessons learned from field and laboratory observations," in Proceedings of the 9th International Conference on Concrete Pavements, pp. 824-835, San Francisco, CA, USA, August 2008.
[16] X. Wang, J. Zhang, X. Wang, P. Taylor, K. Wang, and X. Sun, "Exploration of mechanisms of joint deterioration in concrete pavements regarding interfacial transition zone," Advances in Civil Engineering, vol. 2018, Article ID 3295954, 9 pages, 2018.

[17] S. M. Cramer and R. A. Walls, Strategies for Enhancing the Freeze-Thaw Durability of Portland Cement Concrete Pavements, Wisconsin Department of Transportation, Division of Transportation Infrastructure Development, Bureau of Highway Construction, Technology Advancement Unit, Madison, WI, USA, 2001.

[18] J. J. Valenza and G. W. Scherer, "Mechanism for salt scaling," Journal of the American Ceramic Society, vol. 89, no. 4, pp. 1161-1179, 2006.

[19] K. Wang, G. Lomboy, and R. Steffes, Investigation into Freezing-Thawing Durability of Low-Permeability Concrete with and without Air Entraining Agent, National Concrete Pavement Technology Center, Ames, IA, USA, 2009.

[20] S. Y. Jang, S. Karthick, and S. J. Kwon, "Investigation on durability performance in early aged high-performance concrete containing GGBFS and FA," Advances in Materials Science and Engineering, vol. 2017, Article ID 3214696, 11 pages, 2017.

[21] Expressway \& Transportation Research Institute, Properties of Durability of Sand and Air Void in Concrete Pavement, Korea Expressway Corporation, Gimcheon-si, Republic of Korea, 2010, in Korean.

[22] Expressway \& Transportation Research Institute, A Study of Control and Prevent Method of Alkali-Silica Reaction in Transportation Structures, Korea Expressway Corporation, Gimcheon-si, Republic of Korea, 2011, in Korean.

[23] Korea Expressway Corporation Research Institute (KECRI), Improvement of the Standard Mix Proportions of Cement Concrete Considering Quality Variations, KECRI, Gimcheonsi, Republic of Korea, 2014, in Korean.

[24] Korea Expressway Corporation Research Institute (KECRI), Minimizing of Air Void Spacing Factor to Improve Durability in Concrete Pavement, KECRI, Gimcheon-si, Republic of Korea, 2014, in Korean.

[25] Korea Expressway Corporation Research Institute (KECRI), Mix Design and Performance Evaluation of the Long Life Concrete Pavement Materials, KECRI, Gimcheon-si, Republic of Korea, 2015, in Korean.

[26] Korea Expressway Corporation Research Institute (KECRI), $A$ Study for the Progress of Pavement Maintenance and Repair Practices with Improving Pavement Performance Monitoring System, KECRI, Gimcheon-si, Republic of Korea, 2016, in Korean.

[27] Ministry of Land, Infrastructure and Transport (MOLIT), Korean Highway Bridge Design Code (Limit State Design), MOLIT, Sejong City, Republic of Korea, 2012, in Korean.

[28] RoadKorea, Highway Pavement Condition Survey and Analysis 2004, Korea Highway Corporation (KHC), Songnam-si, Republic of Korea, 2004, in Korean.

[29] RoadKorea, Highway Pavement Condition Survey and Analysis 2005, Korea Highway Corporation (KHC), Songnam-si, Republic of Korea, 2005, in Korean.

[30] RoadKorea, Highway Pavement Condition Survey and Analysis 2006, Korea Highway Corporation (KHC), Songnam-si, Republic of Korea, 2006, in Korean.

[31] RoadKorea, Highway Pavement Condition Survey and Analysis 2007, Korea Highway Corporation (KHC), Songnam-si, Republic of Korea, 2007, in Korean. 
[32] RoadKorea, Expressway Pavement Condition Survey and Analysis 2008, Korea Expressway Corporation (KEC), Songnam-si, Republic of Korea, 2008, in Korean.

[33] RoadKorea, Expressway Pavement Condition Survey and Analysis 2009, Korea Expressway Corporation (KEC), Songnam-si, Republic of Korea, 2009, in Korean.

[34] RoadKorea, Expressway Pavement Condition Survey and Analysis 2010, Korea Expressway Corporation (KEC), Songnam-si, Republic of Korea, 2010, in Korean.

[35] RoadKorea, Expressway Pavement Condition Survey and Analysis 2011, Korea Expressway Corporation (KEC), Songnam-si, Republic of Korea, 2011, in Korean.

[36] RoadKorea, Expressway Pavement Condition Survey and Analysis 2012, Korea Expressway Corporation (KEC), Songnam-si, Republic of Korea, 2012, in Korean.

[37] RoadKorea, Expressway Pavement Condition Survey and Analysis 2013, Korea Expressway Corporation (KEC), Songnam-si, Republic of Korea, 2013, in Korean.

[38] RoadKorea, Expressway Pavement Condition Survey and Analysis 2014, Korea Expressway Corporation (KEC), Songnam-si, Republic of Korea, 2014, in Korean.

[39] RoadKorea, Expressway Pavement Condition Survey and Analysis 2015, Korea Expressway Corporation (KEC), Songnam-si, Republic of Korea, 2015, in Korean.

[40] RoadKorea, Expressway Pavement Condition Survey and Analysis 2016, Korea Expressway Corporation (KEC), Songnam-si, Republic of Korea, 2016, in Korean.

[41] RoadKorea, Expressway Pavement Condition Survey and Analysis 2017, Korea Expressway Corporation (KEC), Songnam-si, Republic of Korea, (in Korean), 2017, in Korean.

[42] ASTM C457, Standard Test Method for Microscopical Determination of Parameters of the Air Void System in Hardened Concrete, American Society for Testing and Materials (ASTM), West Conshohocken, PA, USA, 2016.

[43] M. I. Darter, Report on the 1992 US Tour of European Concrete Highways, Federal Highway Administration (FHWA), Washington, D.C, USA, 1992.

[44] K. Hall, D. Dawood, S. Vanikar et al., "Long-life concrete pavements in Europe and Canada," Report FHWA-PL-07027, Federal Highway Administration (FHWA), Washington, D.C., USA, 2007.

[45] A. Beeldens, C. Ployaert, L. Rens, and P. De Winne, "Belgian specifications for freeze-thaw-resistant pavement concrete," in Proceedings of the 12t International Symposium on Concrete Roads 2014, Prague, Czech Republic, September 2014.

[46] W. Remarque, K. Bollmann, and P. Lyhs, "Innovative concepts for concrete roads further development of the construction," in Proceedings of the 12t International Symposium on Concrete Roads 2014, Prague, Czech Republic, September 2014.

[47] L. Rens, G. K. Niels Groenen, F. Covemaeker et al., "Comparison of two rehabilitation work sites of motorways; single versus double layered CRCP," in Proceedings of the 12t International Symposium on Concrete Roads 2014, Prague, Czech Republic, September 2014.

[48] S. Carrascon and J. Ainchil, "Design \& construction of an experimental two layer concrete pavement motorway section in Spain," in Proceedings of the 12t International Symposium on Concrete Roads 2014, Prague, Czech Republic, September 2014.

[49] ASTM C78/C78M, Standard Test Method for Flexural Strength of Concrete (Using Simple Beam with Third Point Loading), American Society for Testing Materials, West Conshohocken, PA, USA, 2010.
[50] ASTM C672/C672M, Standard Test Method for Scaling Resistance of Concrete Surfaces Exposed to Deicing Chemicals, American Society for Testing Materials, West Conshohocken, PA, USA, 2012.

[51] ASTM C666/C666M, Standard Test Method or Resistance of Concrete to Rapid Freezing and Thawing, American Society for Testing Materials, West Conshohocken, PA, USA, 2015.

[52] ASTM C1202, Standard Test Method or Electrical Indication of Concrete's Ability to Resist Chloride Ion Penetration, American Society for Testing Materials, West Conshohocken, PA, USA, 2012. 


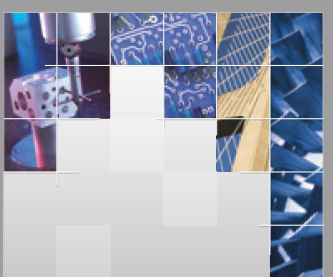

\section{Enfincering}
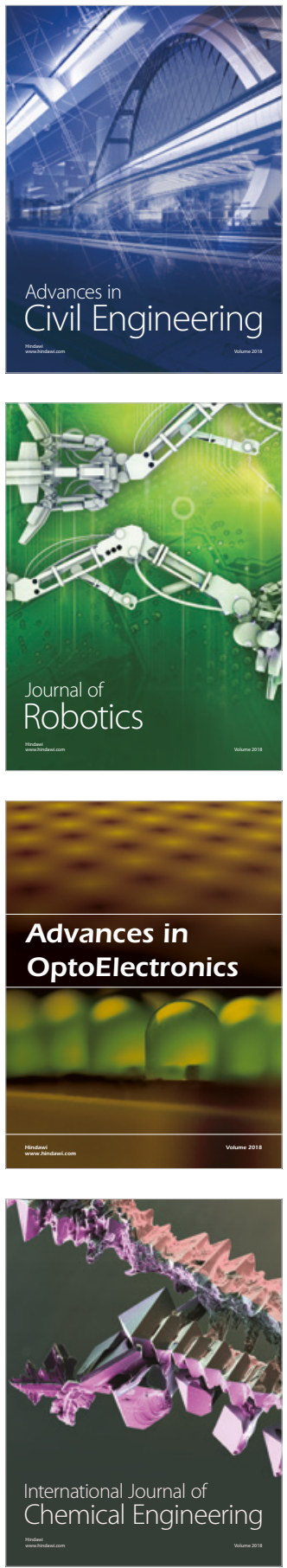

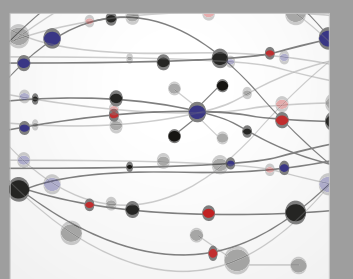

\section{Rotating \\ Machinery}

The Scientific World Journal

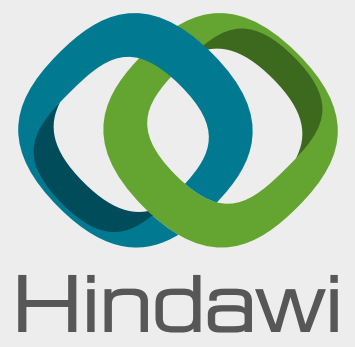

Submit your manuscripts at

www.hindawi.com
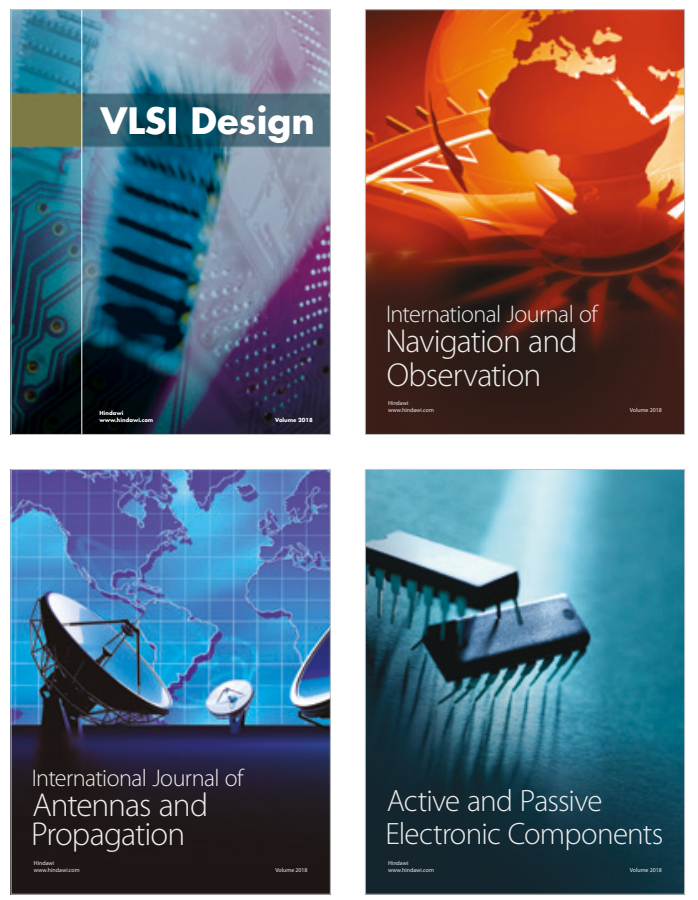
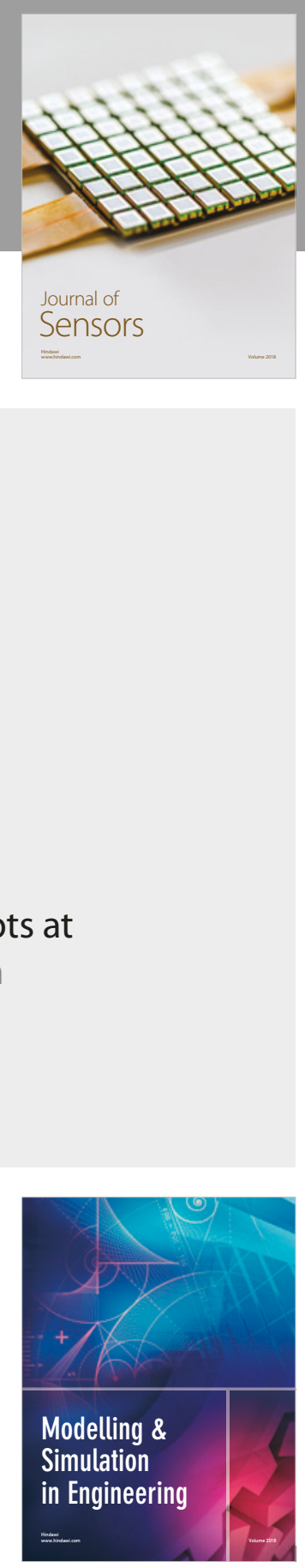

\section{Advances \\ Multimedia}
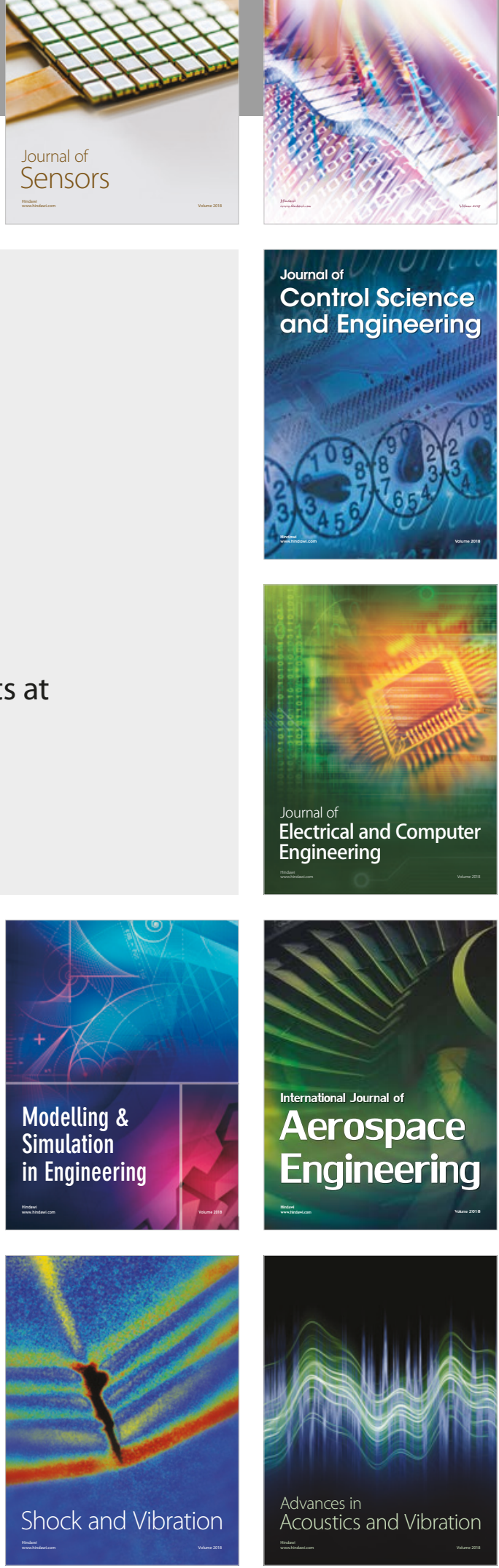